\title{
Determination of the required power for bus hybrid engine
}

\author{
Vyacheslav Rakov ${ }^{1, *}$, Timur Akhmetov ${ }^{3}$, Alexander Capustin ${ }^{2}$ and Anatoly Vostrov ${ }^{1}$ \\ ${ }^{1}$ Vologda State University, Department of automobiles and automobile industry, 160000 Lenin st., 15, Russia \\ ${ }^{2}$ Saint-Petersburg State University of Architecture and Civil Engineering, 190005, St. Petersburg, 2nd Krasnoarmeyskaya st., 4, Russia \\ ${ }^{3}$ Kazan State Power Engineering University, Kazan, Russia
}

\begin{abstract}
This article presents a methodology for determining the required engine power of hybrid city buses. The vehicle's driving cycle and its main technical characteristics were used as the initial data. The calculated change in power on the driving wheels is an intermediate result and is used to analyze the chains of energy transfer from gasoline engine to driving wheels. In this approach, a sequential type of circuit in a hybrid drive is used. A bus weighing 4 tons was considered as an example, and the calculations showed that the maximum power of the internal combustion engine should be $15.2 \mathrm{~kW}$.
\end{abstract}

\section{Introduction}

City buses operate under conditions of frequent acceleration and braking, so the operation mode of the internal combustion engine (ICE) and transmission are constantly changing. Electromechanical hybrid engines fit very well for such working conditions. ICE in such engines is not directly connected to the driving wheels and can operate in the optimal stationary mode, producing energy for traction motors [1,2]. Therefore, when designing hybrid engines, it is especially important to determine the optimal characteristics of ICE, ensuring its minimum specific fuel consumption, low cost and sufficient performance.

To select the required power of ICE hybrid bus engines, a simplified traction calculation is often used, which does not take into account energy losses during energy transfer and power balance when consuming and refilling energy during motion. Thereby, often after manufacturing an experimental car, it turns out that the selected engine operates at low or, conversely, at high loads. This leads to a decrease in efficiency of engine, a lack of power when driving, or an increase in specific fuel consumption. For this reason, many hybrid bus projects have not been implemented, despite the large amount of money spent. Thus, a methodology for calculating the main parameters of a hybrid engine of a vehicle, and, first of all, its main source of energy - an internal combustion engine is needed.

Studies on the adaptation of ICE to unsteady operating conditions were presented by us earlier [3]. Also, some components of method are considered in [4,5]. A number of authors address the issues of modeling hybrid engines for vehicles $[6,7]$.

The presented methodology is used to determine the maximum power of ICE operating in combination with an electric drive. It takes into account mass and aerodynamic characteristics of vehicle, the specified dynamic driving conditions and the characteristics of the drive elements themselves (transmission, electric motor, energy storage, power converter, generator). This methodology includes traction and energy calculation of drive. Both sections are related with each other, which enables to perform a comparative analysis and select the optimal ICE characteristics for a given vehicle, as a function of specified driving cycle. The methodology for calculating the maximum ICE power was modeled and became a part of the algorithm of the GSU-AVTO software [5], which made it possible to carry out theoretical modeling and obtain the necessary characteristics without the cost for making experimental running models.

\section{Materials and methods}

The basis for calculation the maximum power of ICE hybrid bus engine is the driving cycle. It is a set of data on the change in vehicle speed and longitudinal angle of the road plane as a function of time $(v=f(t) ; \alpha=f(t))$. These data sets can be obtained in experiments by recording the change in parameters when moving along a given route or can be set theoretically. Thus, to perform calculation, it is advisable to use the average motion cycle. This paper presents an example of calculation based on the low-speed part of the standard WLTC driving cycle, which has been operating in Europe since 2018 (figure 1) [8]. This cycle consists of a series of accelerations to a speed of not more than $56 \mathrm{~km} / \mathrm{h}$ and braking, including a complete stop. The average speed is $18.9 \mathrm{~km} / \mathrm{h}$, and speed-up during acceleration and braking are also suitable for light buses. For given operating conditions of bus, it is possible to set other types of driving cycles. So, some researchers use bus cycle models for a particular city $[9,10]$.

Using the known traction calculation formulas, the resistance forces acting on bus with a hybrid engine were

* Corresponding author: vyacheslav.rakov@ mail.ru 


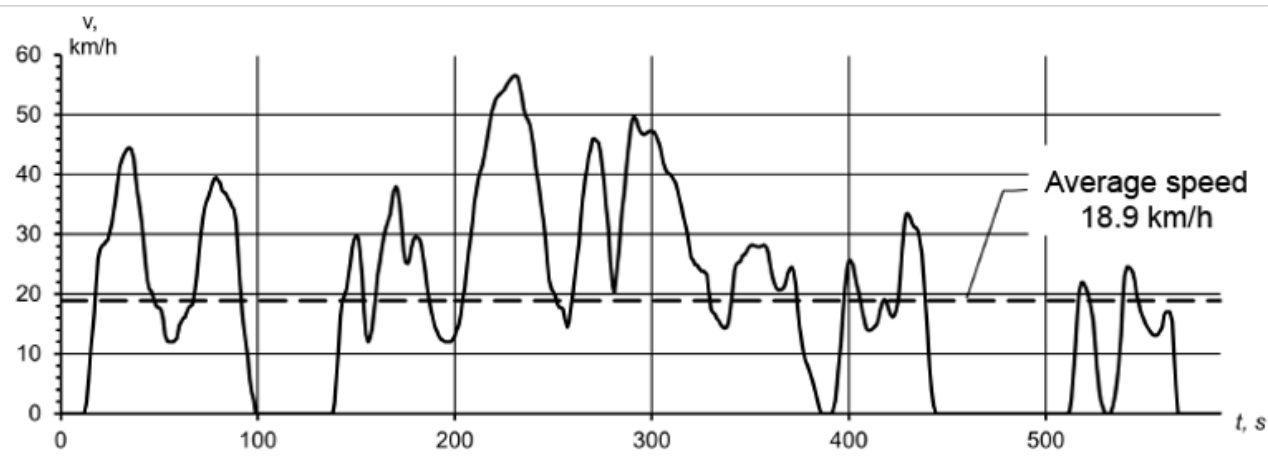

Fig. 1. Low-speed part of the standard test cycle WLTC.

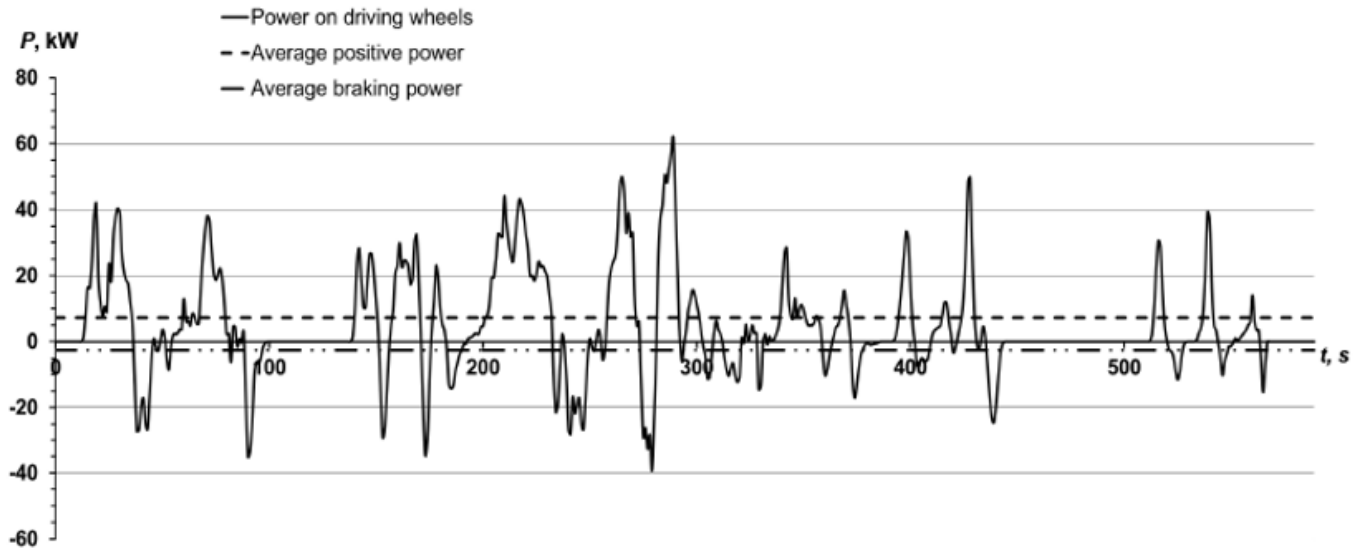

Fig. 2. Change in power on the bus driving wheels.

determined at each $i$-th point: $N_{K i}$ is the rolling resistance force; $N_{v i}$ is the air resistance force; $N_{I i}$ is the inertia resistance force; $N_{P i}$ is the resistance to lift.

The power of traction force on bus driving wheels will be equal to the sum of all powers of resistance forces acting at a given time moment:

$$
N_{T i}=N_{K i}+N_{v i}+N_{I i}+N_{P i},[k W]
$$

Thus, after calculating all the resistance forces, one can find the characteristic of power change of the driving wheels. Figure 2 shows the calculation results for power of the driving wheels of a bus weighing 4 tons when moving according to the standard cycle shown in figure 1.

Further, the obtained change in power of the bus driving wheels is used to analyze energy flows in engine.

The average power of traction force over the entire driving section $N_{P O S . A V E R}$ (figure 2) shows the average value of only positive traction power over the entire calculated section, $n$ is the number of points of the test section. In fact, it is an average power of the hybrid drive without taking into account the energy returned during the recovery (formula 2):

$$
N_{\text {POS.AVER }}=\frac{\sum_{1}^{n} N_{\text {POS.AVERi }}}{n},[k W]
$$

$N_{B R A K . A V E R}$ (figure 2) is the average value of only negative values of traction power over the entire calculated section. In fact, this is the average power returned back to the energy storage:

$$
N_{B R A K . A V E R}=\frac{\sum_{1}^{n} N_{B R A K . A V E R i}}{n},[k W]
$$

Thus, based on expressions 1-3, the ICE power in general terms will be calculated by:

$$
N_{I C E}=\frac{N_{P O S . A V E R}}{K \times \eta_{D R I V E}}-N_{B R A K . A V E R} \times \eta_{P},[k W]
$$

where $N_{I C E}$ is the required ICE power, taking into account losses in drive, $\mathrm{kW} ; K$ is the coefficient of efficient operating mode of ICE for this section (determined experimentally $[3,4]$ ); $\eta_{D R I V E}$ is the drive efficiency; $\eta_{R}$ is the efficiency of recovery on the route. 


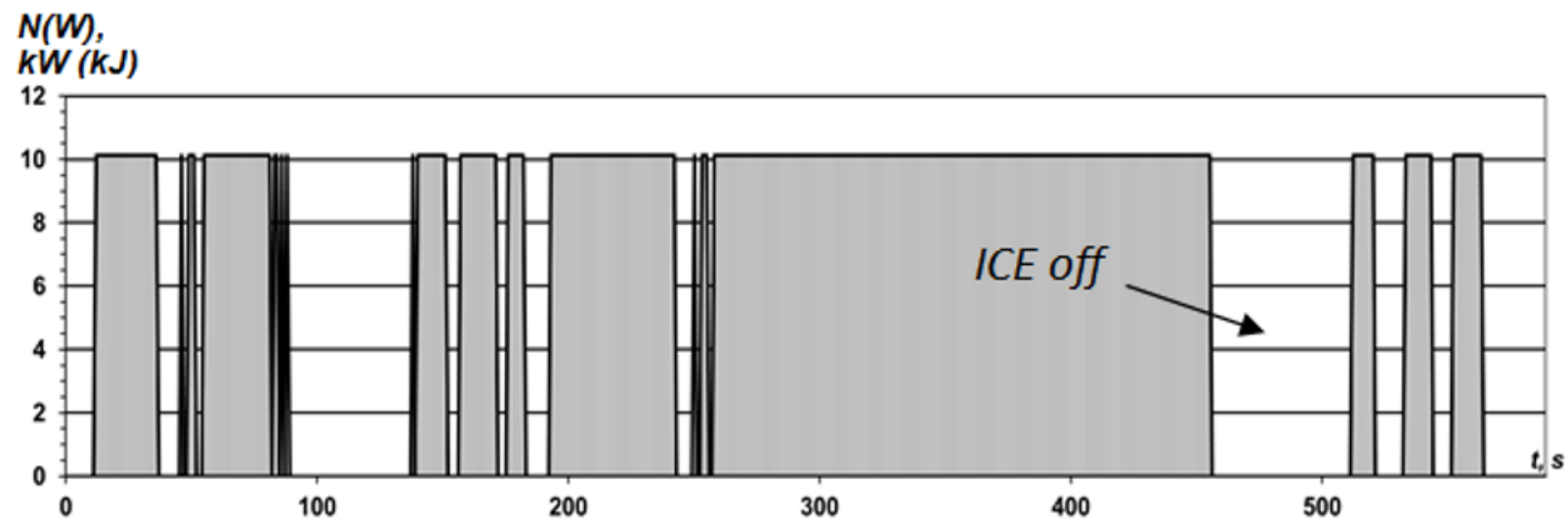

Fig. 3. The developed power of an internal combustion engine of a hybrid power plant.

Further, the power flows between ICE and driving wheels were determined, taking into account the features of the applied typical scheme of a hybrid engine.

A sequential energy transfer scheme is often used in hybrid bus engines [5]. The mechanical connection between the driving wheels and the internal combustion engine in this scheme is completely absent. The advantages and disadvantages of such a scheme were considered by the authors earlier [1]. In this case energy will be transmitted along the following chains:

- From ICE to the generator, then to the traction motor and to the driving wheels $\left(N_{l}\right)$;

- From ICE to the electric generator, then to the highvoltage battery (HVB), then to the traction motor and to the driving axle $\left(N_{2}\right)$;

- During recovery, energy will be transmitted from the driving wheels through the generator to HVB, and further spent on motion again $\left(N_{2}\right)$.

The energy transfer chains in a hybrid engine were described in detail by the authors in $[4,11]$.

Therefore, the required ICE power is made up of all 3 energy transfer chains:

$$
N_{\text {ICE }}=N_{1}+N_{2}-N_{3},[k W]
$$

Figure 3 shows the ICE operating mode, from which it follows that it operates in quasi-stationary mode. The developed ICE power in this case is about $10.5 \mathrm{~kW}$. While calculating $N_{I C E}$ value, it is necessary to take into account the optimal ICE loading mode, which is usually equal to $75 \%$ of the maximum power. Thus, the maximum power of ICE will be more by $25 \%$. One should also take into account power consumed by all onboard devices, which can reach $2 \mathrm{~kW}$. Therefore, taking into account the safety factor $K_{P}$ and on-board energy consumers $N_{C}$, the final ICE power will be calculated using the following expression:

$$
N_{I C E}^{M A X}=K_{P} \times N_{I C E}+N_{C}
$$

\section{Results}

For a hybrid engine of a bus weighing 4 tons when driving in urban conditions, the maximum ICE power should be $15.2 \mathrm{~kW}$. In this case, ICE operates in a quasistationary mode corresponding to the minimum specific fuel consumption. Peak power values resulting from accelerations will be compensated by the energy of buffer storage of electrical energy of sufficient power. The overall balance of electrical energy will always remain constant. In this mode, the hybrid engine of bus will almost always work in the mode of minimum specific fuel consumption. And when there is no load on the driving wheels, ICE will generate energy to charge the buffer drive or will be completely off.

It should be noted that the methodology presented by the authors will work only with a sufficient capacity of high-voltage battery providing a long supply of energy and peak power surges on the bus driving wheels. If necessary, one can use a smaller battery, but the maximum ICE power in this case will be higher. Evaluation of the required battery capacity of a hybrid engine will be considered by the authors in their further papers.

\section{Conclusions}

Thus, the methodology presented by the authors allows one to determine the required ICE power of a bus hybrid engine, at which it will perform the specified transport work with minimum specific fuel consumption.

This methodology can be useful for conducting theoretical research and engineering calculations during design of energy-efficient buses with hybrid engines.

\section{References}

[1] A. Kapustin, V.A. Rakov, Hybrid cars [Gibridnye avtomobili] (Vologda: Vologda State University, 96, 2016).

[2] G. Pistoia, Electric and hybrid vehicles, Power sources, models, sustainability, infrastructure and 
the market (Oxford: The Netherlands Linacre House, Great Britain, 670, 2010).

[3] I.K. Aleksandrov, E.V. Nesgovorov, V.A. Rakov, Tractional Calculations for Vehicles with Adaptive Motors, Russian Engineering Research 30, 2, 122-124 (2010). DOI: 10.3103/S1068798X1002005X.

[4] V. Rakov, V.N. Ivanov, Y.G. Karpov, V.F. Melehin, R.A. Izmailov, V.K. Yun, D.A. Zaripova, Method for determining the basic energy characteristics of elements of a hybrid car engine, IOP Conference Series: Earth and Environmental Science 337, 1 (2019). DOI: $10.1088 / 1755-1315 / 337 / 1 / 012066$.

[5] I.K. Aleksandrov, Determination of hybrid power installation parameters based on trolleybus driving cycle studies [Opredeleniye parametrov gibridnoy silovoy ustanovki na osnovanii issledovaniy yezdovogo tsikla trolleybusa], Alternative fuel vehicles 5, 41, 54-60 (2014).

[6] M.V. Yutt, Principles of building a combined energy installation of a minibus for inter-city transportation [Printsipy postroyeniya kombinirovannoy energoustanovki mikroavtobusa dlya vnutrigorodskikh perevozok], Electronics and electrical equipment of transport 1, 14-16 (2008).

[7] T.J. Boehme, B. Becker, M. Ruben-Weck, M. Rothschuh, A. Boldt, C. Rollinger, R. Butz, H. Rabba, Optimal design strategies for different hybrid powertrain configurations assessed with European drive cycles, SAE world congress, Technical Paper, 1751 (2013). DOI: $10.4271 / 2013-01-1751$.

[8] M. Tutuianu, P. Bonnel, B. Ciuffo, et al., Development of the World-wide harmonized Light duty Test Cycle (WLTC) and a possible pathway for its introduction in the European legislation, Transportation Research Part D: Transport and Environment 40, 61-75 (2015).

[9] H. Wi, J. Park, J. Lee, W. Kim, et al., Development of a City Bus Driving Cycle in Seoul Based on the Actual Patterns of Urban Bus Driving, SAE Technical Paper (2009). DOI: 10.4271/2009-01-2914.

[10] B.H. Wang, Y.G. Luo, J.W. Zhang, Simulation of city bus performance based on actual urban driving cycle in China, Int. J. Automot. Technol. 9, 501-507 (2008). DOI: 10.1007/s12239-008-0060-3.

[11] V.A. Rakov, A.V. Smirnov, Determination of the required power of internal combustion engines of hybrid engines of vehicles [Opredeleniye neobkhodimoy moshchnosti DVS gibridnykh silovykh ustanovok transportnykh sredstv], Engineering Bulletin 4, 29-31 (2010). 